\title{
The roles of family members, health care workers, and others in decision-making processes about genetic testing among individuals at risk for Huntington disease
}

Robert Klitzman, $\mathrm{MD}^{1}$, Deborah Thorne, $\mathrm{MSW}^{2}$, Jennifer Williamson, MS, CGC $C^{2,3}$, and Karen Marder, MD, MPH ${ }^{2,3,4}$

\begin{abstract}
Purpose: To understand how individuals at risk for Huntington disease view the roles of others, e.g., family members and health care workers, in decision making about genetic testing. Methods: Twenty-one individuals (eight mutation-positive, four mutation-negative, and nine not tested) were interviewed for approximately 2 hours each. Results: Interviewees illuminated several key aspects of the roles of family members and health care workers (in genetics and other fields) in decision making about testing that have been underexplored. Family members often felt strongly about whether an individual should get tested. Health care workers provided information and assistance with decision making and mental health referrals that were often helpful. Yet health care workers varied in knowledge and sensitivity regarding testing issues, and the quality of counseling and testing experiences can range widely. At times, health care workers without specialized knowledge of Huntington disease offered opinions of whether to test. Input from families and health care workers could also conflict with each other and with an individual's own preferences. Larger institutional and geographic contexts shaped decisions as well. Conclusion: Decision-making theories applied to Huntington disease testing have frequently drawn on psychological models, yet the current data highlight the importance of social contexts and relationships in testing decisions. This report, the first to our knowledge to explore individuals' perceptions of social factors (particularly family and health care worker involvement) in Huntington disease testing decisions, has critical implications for practice, education, research, and policy. Genet Med 2007:9(6):358-371.
\end{abstract}

Key Words: Genetic testing, Huntington disease, decision making, risk, ethics, health care provider, medical education

Although several aspects of genetic testing decisions among individuals at risk for Huntington disease (HD) have been investigated in the past, social factors and contexts, particularly the roles of others (e.g., family members and health care workers $[\mathrm{HCWs}]$ ) in these decision-making processes have been underexplored, and many critical questions thus remain. Although studies in the 1980s suggested that most at-risk individuals would opt for testing, ${ }^{1-4}$ rates of testing have been lower (e.g., $5-20 \%{ }^{5,6}$ ).

From the ${ }^{1}$ College of Physicians and Surgeons and Mailman School of Public Health; ${ }^{2} \mathrm{De}-$ partments of Neurology and Psychiatry, College of Physicians and Surgeons; ${ }^{3}$ Gertrude $H$. Sergievsky Center; ${ }^{4}$ Taub Institute for Alzheimer's Disease and the Aging Brain, Columbia University, New York, New York.

Robert Klitzman, MD, 1051 Riverside Drive, Unit 15, New York, NY 10032; E-mail: rlk2@columbia.edu

Disclosure: The authors declare no conflict of interest.

Submitted for publication October 13, 2006.

Accepted for publication March 12, 2007.

DOI: 10.1097/GIM.0b013e3180653c5a
Previous studies have assessed knowledge and attitudes toward testing ${ }^{7,8}$ and identified several main reasons for testing (e.g., obtaining certainty, future planning, helping children $^{9-11}$ ) or not testing (e.g., risk to children if one tested positive, lack of a cure, threat to health insurance, testing costs, ${ }^{12}$ fears of depression or problems coping with the result $\left.{ }^{13}\right)$.

However, only a few studies have examined how individuals at risk of HD make decisions. One study found that one third of individuals each "proceeded to get testing without expressing any doubts," "evolved" toward the decision, or experienced a pivotal moment when they decided to test. ${ }^{14}$ Models, drawing on the Stages of Change theory, ${ }^{15}$ have suggested that individuals pass through four stages, and go from being unaware and unengaged to deciding to test, not test, or postpone testing. ${ }^{16,17}$ But the impact of social factors on such stages and processes has not been explored.

To understand genetic testing decisions, several additional theoretical models have been proposed as well, but have also tended to be individual based, drawing on psychological rather than sociological or interpersonal models. For example, the 
Health Belief Model, based on studies of smoking cessation, suggests that health behavior is shaped by perceived susceptibility, disease severity, and costs and benefits of the behavior. ${ }^{18,19}$ Models of stress and coping have described coping strategies as either "problem" or "emotion" focused. ${ }^{20}$ However, limitations have been described in applying these two models to genetic testing. ${ }^{21}$ Health information in general has also been described as meeting either cognitive or emotional needs, ${ }^{22}$ and individuals have been described as risk averse $^{23}$ and as either seeking ("monitoring") or avoiding ("blunting) information. ${ }^{24,25}$ But, again, social factors and contexts may play critical roles in health decisions in ways that have not been linked to these theoretical models.

Indeed, sociologists, anthropologists, and others have long described how individual decisions and behaviors in general often take place in the context of social systems and relationships. ${ }^{26,27}$ Sociological interactions and relationships can involve a broad array of dynamic, complex pressures and input that individuals can accept, resist, or negotiate. ${ }^{28}$

Social factors have been mentioned as playing roles in decisions concerning aspects of other genetic diseases, and of coping with HD. For example, for breast cancer testing, understanding of risk has been found to operate in dynamic interpersonal relationships and to be subjective. ${ }^{29}$ Familial contexts can shape experiences of being at risk of $\mathrm{HD},{ }^{30}$ and HD testing can affect family relationships and communication (e.g., changing caregivers' roles). ${ }^{31,32}$ An individual who tests mutation-positive must decide within his or her family what, when, and to whom to disclose the test results. ${ }^{33}$ In reproductive decisions for $\mathrm{HD}$, perceived responsibilities toward others can play crucial roles. ${ }^{34}$ However, these perceived responsibilities can conflict with each other and with a patient's own preferences, creating dilemmas. ${ }^{35}$ One Australian study noted that, as one aspect of HD testing decisions, individuals considered hypothetical reactions from family members (i.e., how family members might react) and perceptions of a family member's best interests. These imagined responses affected decisions to test or not. However, this report did not examine many other key aspects of these inputs, e.g., whether family members in fact communicated directly with family members about these testing decisions, and, if so, what exactly was said; whether conflicts ever arose concerning testing decisions, and, if so, how and when; and how at-risk individuals viewed or responded to these inputs. ${ }^{36}$

HCWs, too, may affect a patient's decision making about HD testing, but their role in doing so has also received little attention. The Huntington's Disease Society of America (HDSA) has developed guidelines for genetic counselors for testing, ${ }^{37}$ but many questions arise as to how well and frequently these recommendations are followed and how at-risk individuals view them. For genetic diseases overall, genetic counseling affects reproductive plans. ${ }^{38}$ The experiences of patients with genetic counselors (GCs) have been explored regarding other diseases, but not HD. For genetic diseases other than HD, clients felt that GCs could have provided more input, particularly concerning disclosure. ${ }^{39}$ Of patients testing for colorectal cancer, $53 \%$ reported that they might have used professional psychological support had it been provided. ${ }^{38}$ For Tay-Sachs disease and fragile $\mathrm{X}$ syndrome in Israel, the major reason for not having testing done was not being referred by a physician for the tests. ${ }^{40}$ The only study that we were able to find concerning HD counseling procedures, conducted in the early 1990s, suggested that, overall, participants in a research protocol were satisfied with the experience, although patients and clinicians differed in their views of the importance of various aspects of the protocol. ${ }^{41}$

Questions arise, too, concerning interactions between individuals at risk for HD and HCWs in other fields. Several studies have explored other diverse aspects of HCW knowledge, attitudes, and behavior concerning genetics. For example, of primary care providers (PCPs), $31 \%$ to $56 \%$ have ordered genetic tests of some kind for patients, ${ }^{42,43}$ and $95 \%$ of physicians think that they have responsibilities to counsel patients about genetic testing in general. ${ }^{44}$ However, most PCPs have been found not to feel qualified to recommend genetic testing. ${ }^{45}$ Physicians have also been found to have limited knowledge about genetics. ${ }^{46}$ Among general practitioners (GPs), gynecologists, and pediatricians, deficiencies in knowledge increased with length of time since medical graduation. ${ }^{47}$ Medical trainees reported insufficient genetics education and being unprepared for colorectal cancer screening, and they have been found to be deficient in knowledge, risk assessment skills, ${ }^{48,49}$ and notification of at-risk relatives..$^{50}$ Among a diverse group of physicians, $28 \%$ did not have access to a GC, ${ }^{43}$ and $23 \%$ of PCPs reported that genetic consultation was very difficult to obtain, particularly in rural areas. ${ }^{51}$ Indeed, $<19 \%$ of patients who underwent genetic testing for colorectal cancer received genetic counseling beforehand. ${ }^{52}$ Physicians were more likely to refer for, or order, a genetic susceptibility test if patients asked about it, ${ }^{42}$ and the strongest predictor of PCP recommendations or referrals for testing was patient inquiry. ${ }^{53}$

Past literature and models concerning HD testing have also underexamined whether and how larger social contexts, such as the health care system, might be involved as well. Several previous studies about HD testing were conducted shortly after the HD test was developed, ${ }^{30}$ but since then, more than 10 years have passed, during which the HD community has discussed testing more, electronic records have burgeoned, the U.S. Health Insurance Portability and Accountability Act took effect, genetic discrimination has been documented, ${ }^{54}$ most states have adopted genetic antidiscrimination legislation, GCs have gained more experience, and patterns of U.S. insurance coverage have shifted. ${ }^{55}$ Preimplantation genetic diagnosis (PGD) has also become available, in which embryos are screened for a genetic mutation, and only unaffected embryos are implanted. ${ }^{56,57}$ with or without the presence of mutationpositive embryos being disclosed to the parents. These phenomena suggest the possible importance of considering broader social and historical contexts in making and understanding testing decisions.

These questions about the roles of others in genetic decision making are of increasing significance, given the increases in the 
numbers of genetic tests available and direct-to-consumer marketing of many such tests through the Internet. ${ }^{58}$ At the same time, suggestions have been made to decrease the amount of counseling for genetic diseases other than HD. ${ }^{59}$ The further spread of managed care may also make referrals to specialists increasingly difficult to obtain, taking time and effort.

\section{METHODS}

On theoretical grounds, Geertz ${ }^{60}$ has advocated studying aspects of individuals' lives and social situations not by imposing external theoretical structures, but by trying to understand individuals' own experiences, drawing on their own words and perspectives to obtain a "thick description." Hence, to understand most fully the range of factors and issues that may be involved in genetic testing decisions, we used qualitative methods and, as shown in Table 1, interviewed in-depth 21 individuals (eight mutation-positive for $\mathrm{HD}$, four mutation-negative, and nine not tested) for 2 hours each. Of these, seven were symptomatic and 14 were asymptomatic. These individuals

Table 1

Characteristics of sample

\begin{tabular}{|c|c|c|c|c|c|}
\hline Subject ID & Sex & Race & Symptom status & Test status & Marital status \\
\hline 1 & $\mathrm{~F}$ & $\mathrm{~W}$ & Sx & NT & M \\
\hline 2 & $\mathrm{M}$ & B & Sx & NT & M \\
\hline 3 & M & W & Asx & NT & S \\
\hline 4 & $\mathrm{M}$ & W & Asx & + & S \\
\hline 5 & M & W & Asx & + & S \\
\hline 6 & $\mathrm{M}$ & $\mathrm{W}$ & Sx & + & S \\
\hline 7 & $\mathrm{~F}$ & $\mathrm{~W}$ & Asx & + & M \\
\hline 8 & $\mathrm{~F}$ & $\mathrm{~W}$ & Asx & NT & M \\
\hline 9 & $\mathrm{~F}$ & W & Asx & NT & M \\
\hline 10 & $\mathrm{~F}$ & B & Asx & NT & S \\
\hline 11 & M & W & Asx & - & M \\
\hline 12 & $\mathrm{~F}$ & W & Asx & - & M \\
\hline 13 & M & W & Asx & - & M \\
\hline 14 & $\mathrm{M}$ & W & Asx & + & $\mathrm{M}$ \\
\hline 15 & M & W & Sx & + & $\mathrm{M}$ \\
\hline 16 & $\mathrm{~F}$ & W & Asx & NT & $\mathrm{D}$ \\
\hline 17 & M & $\mathrm{L}$ & Asx & NT & S \\
\hline 18 & M & $\mathrm{W}$ & Sx & + & S \\
\hline 19 & $\mathrm{~F}$ & W & Sx & NT & S \\
\hline 20 & $\mathrm{M}$ & W & Sx & + & $\mathrm{M}$ \\
\hline 21 & $\mathrm{~F}$ & W & Asx & - & $S$ \\
\hline
\end{tabular}

B, black; W, white; L, Latino; Asx, asymptomatic; Sx, symptomatic; NT, not tested; + , mutation-positive test result; -, mutation-negative test result; $\mathrm{M}$, married; S, single; D, divorced. represented a diverse sample in terms of education, occupation and time since testing, as can be seen in Table 2.

Participants were recruited from an HD clinic that has a predictive testing program. Staff at the clinic approached individuals who were at risk or had a clinical diagnosis regarding the study. The staff reviewed the current HD center database of active patients and attempted to ask all individuals who underwent presymptomatic testing or who were at risk if they would participate. Participants were either patients or at-risk family members and as such had had some previous interaction with the staff. In all, 28 individuals were approached about participating, of which 21 (75\%) did so. With each participant, the principal investigator (PI) conducted a confidential in-depth semistructured interview concerning experiences of being at risk of $\mathrm{HD}$ and of undergoing the process of testing and/or learning one's genetic status. Interviews were conducted at participants' offices or homes or in the PI's office, whichever was more convenient for participants, and took approximately 2 hours, although varying somewhat in length. The Columbia University Department of Psychiatry Institutional Review Board approved the study, and all participants gave informed consent. Relevant sample sections of the semistructured interview guide are attached (Appendix), through which we sought to obtain detailed descriptions of the process of individuals' decisions concerning testing and related issues.

In our methods, we have adapted elements from grounded theory, as described by Strauss and Corbin ${ }^{61}$ because we were interested in understanding a social process. We have used these methods in several other studies involving genetics ${ }^{35}$ and other aspects of health behavior and doctor-patient relationships and communications. ${ }^{62-68}$ Specifically, grounded theory involves both deductive and inductive thinking, building inductively from the data to an understanding of themes and patterns within the data, and deductively drawing on frameworks from previous research and theories. For example, interviewees introduced topics such as differences in experiences with the process of genetic counseling itself that were then explored further in these and other interviews. Our approach was informed constant comparison in which data from different individuals were compared for similarities and differences to see whether these suggested hypotheses. Constant comparison generates new analytic categories and questions and checks them for reasonableness. During the ongoing process of indepth interviewing, we repeatedly considered ways in which participants resembled or differed from each other in their decisions and in their social contexts and how these decisions and contexts may be related. For example, we compared those participants who decided to test versus not test versus delay testing, those who thought the process was "good" versus "bad," and those who thought the process was "too long" versus was "not too long." As shown below, in these comparisons, input from others (e.g., family members and HCWs) were found to play important roles. We also examined and compared types of such interactions (e.g., individuals agreeing versus disagreeing with the input). Transcriptions and initial analyses of interviews were done during the period in which the 
Table 2

Additional data on interviewees

\begin{tabular}{l}
\hline Gender \\
Male \\
Female \\
Race \\
White \\
Black \\
Latino \\
Education level \\
Some graduate \\
4 yr college \\
$<4$ yr college \\
High school \\
$<$ High school \\
Marital status \\
Married \\
Divorced \\
Single \\
Profession \\
Professional \\
Blue collar \\
Housewife
\end{tabular}

No. of children

0

1

2

Testing status

Positive

Negative

Untested

Symptom status

Symptomatic

Asymptomatic

No. of yr since testing

$<1$

1

2

3

$\geq 5$ interviews were being conducted and helped guide subsequent interviews. Interviews were conducted until "saturation" was reached (i.e., "the point at which no new information or themes are observed in the data" 61,69 ).

Once the full set of interviews was completed, subsequent analyses were conducted in two phases, primarily by the PI together with a research assistant (RA) who had social science training. At several points during the coding process, we also received input from an additional senior expert in qualitative research. In phase I of the subsequent coding, the PI and the RA independently examined a subset of interviews to assess factors that shaped participants' experiences, identifying categories of recurrent themes and issues that were subsequently given codes. These two coders assessed similarities and differences between participants, examining themes and categories that emerged, ranges of variation within categories, and variables that may be involved. The coders systematically coded blocks of test to assign "core" codes or categories. While reading the interviews, a topic name (code) was inserted beside each excerpt of the interview to indicate the themes being discussed. The coders then worked together to reconcile their independently developed coding schemes into a single scheme, developing a coding manual and examining areas of disagreement until reaching consensus between them (i.e., when each coder's view of a phenomenon or theme raised by a participant was reconciled into a coherent understanding of it). New themes that did not fit into the original coding framework were discussed, and modifications were made in the manual when deemed appropriate.

In the next phase of the analysis, we subdivided thematic categories into secondary or subcodes, and then refined and merged these, when suggested by associations or overlap in the data. Codes and subcodes were then used in analysis of all of the interviews. Major codes (or categories) of text included, for example: discussions of counseling experiences, timing of testing decisions, and input from family members and HCWs regarding decisions. Subcodes (or subthemes) were conceptual and thematic subdivisions of these larger categories and included pros and cons of the counseling process (e.g., empathy of GC, views of the counseling process as repetitive or overly long), types of interactions with family members or HCWs (e.g., support or opposition concerning testing), and responses to the input (e.g., deciding nonetheless to test, delay, or not test). To ensure coding reliability, these two coders analyzed all interviews. We examined areas of disagreement until consensus was reached. To ensure trustworthiness, we consulted frequently at multiple points with an external senior qualitative researcher and triangulated the data with existing literature relating to HD and other genetically associated diseases, as discussed above. The authors include trained clinicians who have worked closely with patients at risk of HD for several years. We thus triangulated the data with cumulative experiences from several years of intensive clinical work. These data also have a certain face validity that, we would suggest, further substantiates their trustworthiness. We have presented below text from 
the interviews to allow readers to judge these data for themselves as well.

\section{RESULTS}

Several critical themes arose concerning views of the roles of others, particularly family members and HCWs, in decisionmaking processes regarding HD testing. Overall, during the decision-making process, family members and HCWs often felt strongly whether an individual should get tested or not. Interpersonal conflicts and pressures could ensue. As depicted in Table 3 , a $2 \times 2$ grid or table emerged in which an individual may or may not want testing and others may want or not want the individual to be tested. (Note: The identification number of each subject, corresponding to the information in Table 1 , is indicated by a bracketed superscript.)

\section{Roles of family members}

Family members involved in these decisions included spouses, siblings, parents, and adult offspring. On the one hand, such family members can push for testing.

My wife wanted . . an answer: see what's going on. So she pushed me. After my mother's death, I was depressed. She thought that having the test would eliminate one possibility. ${ }^{[20]}$

This man at first opposed testing, but finally acquiesced. Although his wife felt the test could help diagnostically, that rationale did not sway him, at least initially.

Families may urge testing for several reasons, arguing, for example, that for a member not to test was unfair to them. As one man said to his untested brother: "that's fine for you not to get tested, but it's not very fair for your wife and your children." ${ }^{[13]}$ Hence, at times individuals had to weigh their own preferences and desires concerning testing against others' sense of that individual's responsibilities to these others. Here, this participant had to weigh his sense of autonomy versus others' sense of justice and of his ethical obligations to them.

Table 3

Preference of the at-risk individual versus others concerning the individual undergoing genetic testing

Preferences of others (e.g., family members or HCWs)

Favor Testing

$$
\text { Against testing }
$$

\begin{tabular}{|c|c|c|}
\hline $\begin{array}{r}\text { Favors } \\
\text { Testing }\end{array}$ & Both favor testing & $\begin{array}{l}\text { Individual favors } \\
\text { testing, while others } \\
\text { oppose testing }\end{array}$ \\
\hline $\begin{array}{l}\text { Against } \\
\text { Testing }\end{array}$ & $\begin{array}{l}\text { Individual opposes } \\
\text { testing, while others } \\
\text { favor testing }\end{array}$ & Both oppose testing \\
\hline
\end{tabular}

Not surprisingly, at-risk individuals did not always welcome such pressure (e.g., "I don't want to be in a relationship where I'd feel even the slightest push that I should be tested." [5])

At times, individuals decided to undergo testing to address adult offsprings' worries or concerns about reproductive decisions. Without having to undergo testing themselves, adult offspring could then learn whether they were, in fact, at risk of having the gene and transmitting it to their progeny. These offspring could then avoid potential discrimination to themselves (e.g., in obtaining insurance) and decide whether they should undergo expensive PGD.

Yet such plans to test oneself before becoming a grandparent were not always easy to carry out, as adult offspring could become pregnant without forewarning their parents.

I had testing done-for my children. One's married and just had a baby. I was trying to get it done before that happened, but he had a baby quicker than I thought. . I wanted them to have all the information available to them before they were going to have children. ${ }^{[14]}$

A parent's testing could also confront his or her adult offspring with unwelcome bad news and fears.

Conversely, concerns about family members led some individuals to decide not to test because they felt that the result, if mutation-positive, might upset their offspring and create problems when offspring tried to obtain insurance (i.e., if asked about a family history of genetic testing). Hence, individuals decided not to test to avoid having to disclose painful news to current progeny.

My older brother... decided he doesn't want to know. If he knows, he'll worry more about the kids developing it, and what do you tell the kids? ${ }^{[4]}$

Individuals made testing decisions in response to anticipated desires or responses of others that may or may not be accurate. At-risk individuals may want to test, but do not do so because of a spouse's opposition as well.

The only thing stopping me is my husband. I want to get tested by the time my oldest son is $18 \ldots$... My husband is never gonna agree about it. We're going to have a fight about this. ${ }^{[8]}$

Her husband opposed her testing because he wanted to have another child before she tested, and he wished to avoid stressing her and their relationship.

He does not want me to be tested because he feels: "We have such a good life right now, why chance that? Why spoil a good thing?"

... He's scared I will find out I carry the gene and be nervous or sad. ${ }^{[8]}$

They have discussed the decision, and she has, for the moment, yielded to his wish. Her anticipation of further conflict prompted her to continue to defer testing.

Other family members may oppose an individual getting tested because they feel the individual is not old enough to know and/or would not handle the information well (e.g. "My sister wants to test. But I don't think she should. She's too young. She'd base too many big decisions on it."'[1]) Indeed, 
feelings arose that for others "ignorance is bliss." As this woman said about daughter, "I would just like to see her have 10 years with a good life of not knowing." ${ }^{11]}$ Again, these beliefs involve judgments that may be subjective (i.e., of what is best for the individual) and be perceived as paternalistic.

Family members' encouragement of testing can also encounter patient denial. Such "denial" may represent either psychological resistance to the possibility of testing or psychiatric symptoms of the disorder that can in turn impair personality and judgment.

\begin{abstract}
My brother was very resistant. Maybe. . . he was already symptomatic . . and that might have been affecting his discussion with me ... He doesn't know how sick he is. You can't tell him, and he can't understand because cognitively, he's impaired:... "I' $m$ fine. I'm getting better. . . My brain's growing back."[13]
\end{abstract}

Hence, direct symptoms of the disease can themselves affect testing decisions. Family members who feel that an individual's opposition to their preferences is not justified could then continue to pressure that individual.

\section{Roles of HCWs}

HCWs, too, influenced HD testing and counseling decisions and varied in their approaches and responses to testing. While GCs focused on genetic testing, at-risk individuals interacted with a range of other HCWs as well, including physicians in different fields, concerning HD. Overall, HCWs engaged in several kinds of interactions, providing information about the test, and assistance with the decision-making process. At times, HCWs without specialized knowledge about HD (i.e., who were not neurologists, clinical geneticists, or GCs) also offered opinions of whether an at-risk individual should or should not undergo testing. In these interactions, HCWs varied in their knowledge and sensitivity regarding these issues. In turn, atrisk individuals responded to the HCW input in varying ways.

HCWs could provide important information about the availability and the pros and cons of the test (e.g., of whether, when, and how to test). GCs, in particular, offered useful information and suggestions and addressed the issues and questions involved. For example, GCs often made helpful suggestions as to when to test, recommending doing so only after an at-risk individual obtained insurance, so as not to be found later to have a "preexisting condition" that could impede insurance coverage.

HCWs also helped individuals clarify the dilemmas the latter faced, which were not always easy. A GC's professional stance of relative neutrality could clash with physician training to be more directive with patients and to recommend treatments and tests, occasionally even paternalistically. HCWs often thought that individuals should take the test if the latter were "the type of person who does better knowing." Yet it was unclear how exactly to define, assess, and predict this trait and know in advance if one fit this category, especially with regard to this unique information. GCs could help individuals assess the presence or absence of this trait, but to do so could take a somewhat long period of time.
I was very much on the fence. So, my 6-8 months with the genetic counselor became about where I actually am... I always assumed I was a person who did better not knowing, but that was not the case. ${ }^{[12]}$

HCWs can also take more active stances, either encouraging or discouraging testing. Here, HCWs may differ by profession or specialty: while GCs are trained to be neutral or nondirective, other HCWs, such as GPs, may not be as sensitive or fully appreciate the psychic costs involved.

It seems like the MDs you run across think testing is a great idea. They say, "Just find out!" How dare they? Unless they are at risk... I got that from my primary care doctor. ${ }^{[12]}$

Physicians outside of neurology or genetics could lack much experience with HD or genetics.

The doctors I see don't all know that it's a dominant gene-that there's 50\% chance of inheritance. They sort of know it's a fidgety disorder, but they don't really know anything about it. They'll ask me questions: "Is it a dominant gene? What are the symptoms?" ... Or they'll say, "Huntington's, oh, I remember that somewhere." But they don't know any of the facts about it ... GPs don't know. [21]

HCW sensitivity also varied and could be suboptimal, in part due to poor education. Emergency department staff, for example, may be relatively unaware of broader issues concerning HD. One man's father with HD had "health obsessions" and frequently wanted to visit the emergency department where "doctors didn't know exactly what HD was. They just didn't know how to treat him ... They think he's not responsive ... The doctors were clueless." [17]

At times, HCWs without specialized knowledge about HD expressed strong opinions about the test and about whether an individual should undergo it. PCPs may be wary of the testing process and discourage it, in part because of their own beliefs about its value or utility.

My doctor told me, "go away. Don't be silly. Why would you want to have a test? There's much more chance of you dying of a heart attack or breast cancer..." I didn't like that response. But I didn't do anything about it for a few years. He should have put me in contact with the HD association ... [21]

In this instance, the doctor's response delayed, but did not ultimately prevent, testing. But other at-risk individuals may not in the end oppose their physicians' recommendations.

At-risk individuals may also perceive HCWs, including GCs, as disapproving of certain reasons for wanting to be tested.

The staff said, "you're not being tested for a reason such as wanting to start a family." I did not have a good reason. I just wanted to know. They didn't think that was a good enough reason ... ${ }^{[8]}$

This woman thus deferred testing, but saw the staff as judging her reasons for wanting to be tested. Questions arose here of whether HCWs' judgments were always appropriate or may occasionally be too paternalistic and of what constituted a "good enough" reason. This woman's account also underscored the degree to which HCWs served as key gatekeepers for 
this genetic test. The newness and potential controversies surrounding this test, compared with others, may give physicians particularly key roles in these decision-making processes.

The counseling process itself is designed to compel individuals to consider fully all the options, but because that process takes time, tensions can emerge between HCWs and at-risk individuals who do not appreciate HCWs' motivations and wish to be tested sooner.

I ran to the genetic counselor the day before my vacation. I was fighting with staff: they said, "We'd really like you to wait six months." "How dare you tell me I have to wait?"[8]

At times, feelings arose that GCs were biased, warning of potential dangers of genetic knowledge. "They tend to terrify you to a certain extent, obviously in hopes of scaring off anyone too sensitive to be able to take the answer in the end."[5] This perception of bias may or may not be accurate, but reflected some individuals' beliefs and, as such, is of note.

A few interviewees felt that medically-oriented physicians tended to favor testing, leading other HCWs to be more wary, in part as a result.

\section{Maybe that's why the social workers tend to swing so far to the other side... Social workers, psychiatrists, and psychologists tend to be a little bit more respectful about how hard it must be, and acknowledge that they have no idea what you're going through. Those medical people don't know. ${ }^{[12]}$}

Again, physicians may differ by specialty and training in making recommendations, communicating empathy, and recognizing the difficulties of the decision-making process.

\section{Friends}

Individuals can receive input about testing decisions from not only family members and HCWs, but friends as well. These unaffected outsiders may or may not be sensitive to the complexities and stresses involved in the decision.

People outside the family think "I would have been tested years ago. I don't know how you waited so long." People don't understand: it's just not easy. ${ }^{[8]}$

Commonly, outsiders were seen as not comprehending the difficulties involved in these testing decisions. "I wish people understood just the nightmare of what it is." [13]

\section{Balancing social input and other factors}

As suggested above, an at-risk individual often had to balance these multiple, at times competing inputs against both each other and his or her own desires and preferences. Participants all agreed that ultimately, testing decisions should be made by the individual. Yet weighing these often opposing issues could prove difficult. For example, parents had to balance their own desires not to know their gene status against their perceived obligations to undergo testing to help their current and future children. They frequently prioritized testing to help their children over fears of discrimination to themselves.
In balancing these conflicting issues, other disease-related events commonly played key roles. An at-risk individual could follow others' preferences for a period of time until symptoms become clear. Often, the final straw was when symptoms progressed to the point of impairing significant functions, particularly driving a car. At times, individuals waited to test until confronting particular personal or professional junctures, e.g., deciding to test when forced to make major reproductive or career decisions.

It came to a point where not knowing was as bad as having it. You convince yourself you have it, so you might as well find out if you have it or not... Should I go on to do a PhD, or have kids early. . career or family?... [21]

Here, consideration of potential future offspring helped sway the decision.

Testing could also be deferred until marriage or being at a "stable point," defined in various ways (e.g., having support from others). The cost and time involved in the process of counseling and testing could also deter testing. "I found out that I had to go through 3 months of therapy and that it costs almost $\$ 1,000$ to be tested. I don't want to know that bad."[16] This woman had to balance desire for the information against several costs entailed and was most swayed by the latter. Testing could be delayed until the resources to pay for it, including insurance, became more available.

A very big issue was money - the cost of the test. I was working, but not at a job with insurance. So, at first I didn't have the mon-

ey... I wondered, "should I do this on insurance?"[15]

Obstacles of time and money were weighed with additional psychological factors, but could also represent justifications for not testing (i.e., when individuals also feared confronting the prospect of the disease itself).

As mentioned earlier, the content of the counseling process impeded such haste as well. A few decided they wanted to test immediately, but even they, in retrospect, came to see such eagerness as overly rash. In fact, even to learn how to arrange for testing was not always easy. ("I picked up the Yellow Pages, and called labs, saying 'Do you run this test?' They all said, 'you can't just have this test done."'[8])

As indicated above, at-risk individuals were thus influenced by others and by social contexts in decisions about not only whether, but when to enter the counseling process.

\section{Views of the counseling and testing processes themselves}

As shown in Table 4, interviewees suggested that the quality and quantity of the testing and counseling processes themselves varied widely in several ways.

Institutions that conducted testing ranged from specialized HD centers with strong social service supports to PCPs' offices. Hospitals, clinics, and offices often differed in their experiences and abilities with HD diagnosing and testing. Some institutions had handled relatively few previous cases.

My sister is in a private hospital. The doctor said they were $90 \%$ positive it was HD, but wanted to test. I said, "Has the hospital 
Table 4

Views of the testing and counseling processes themselves

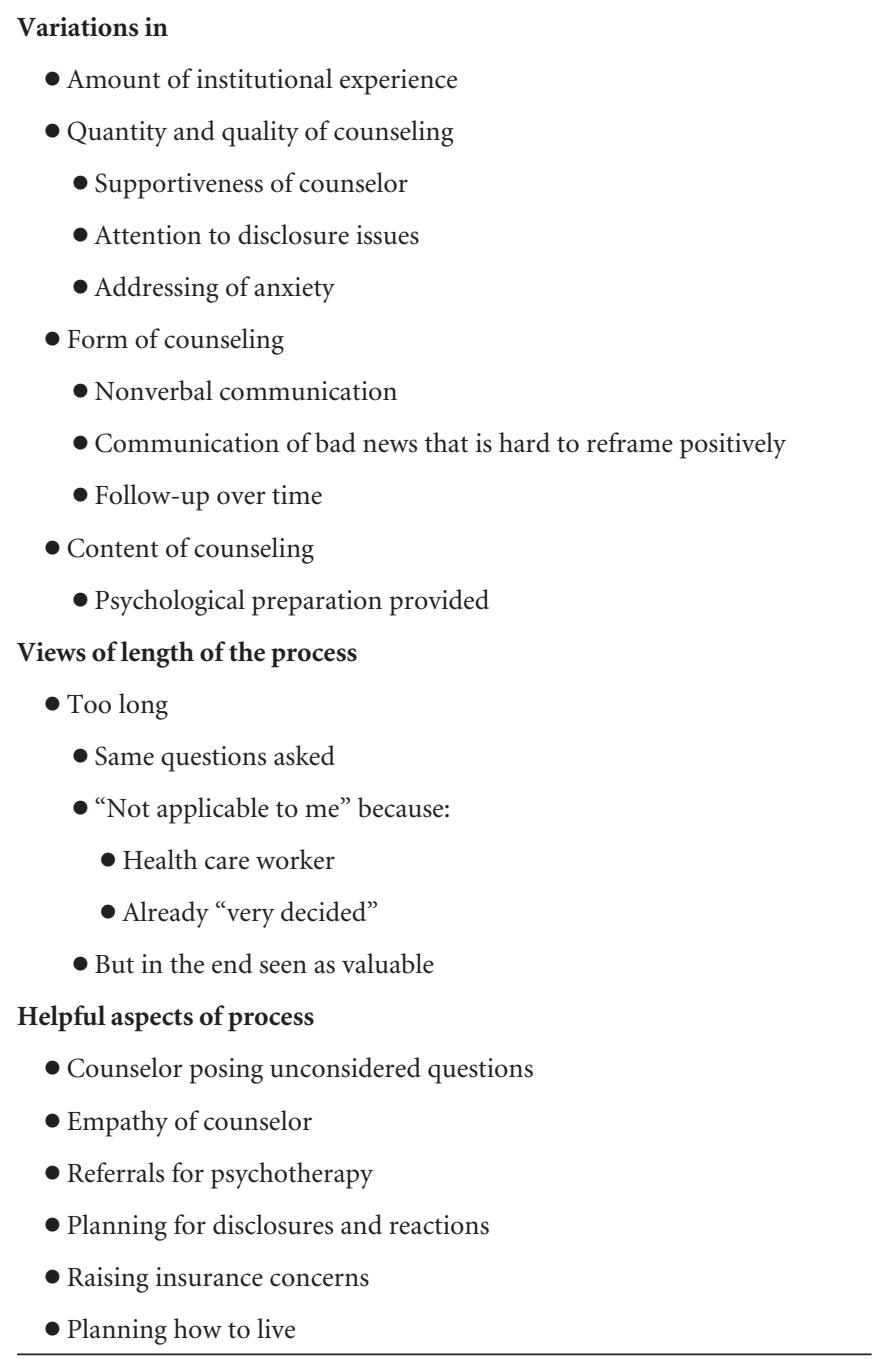

ever dealt with ... HD before?" She said, "No." "Has the doctor personally ever dealt with...HD?" "No"... This pissed me off... [7]

Such differences affected individuals' decisions and experiences. Institutions could provide more or less emotional support, and occasionally counseling was minimal, resulting in suboptimal testing experiences.

My brother didn't go through a program. A psychiatrist has been giving him medications for his obsessive-compulsive disorder. My brother goes once every 3 months, not routinely. They don't have a strong connection. This doctor wrote the prescription for the test. That was it . . No counseling, no nothing, just that. That was a mistake. ${ }^{[13]}$

Other times, there was more counseling, but it still fell short, failing to provide sufficient follow-up or support over time.

The doctor said, "If you need to come back, talk to us." I had his office number, but that was it. I called . . but they were moving the office. I tried to reach out, but couldn't get anyone... They never got back to me. ${ }^{[14]}$

In particular, staff did not always sufficiently help anticipate questions of how and to whom to disclose test results. ("I didn't know who to tell, or what to say. I wasn't prepared for it." ${ }^{[14]}$ )

Anxieties persisted throughout these processes, even after individuals decided to have blood drawn, and assessments and treatments of anxiety ranged as well. Fears can hover prominently not only before and during the counseling process, but even after individuals decide to test. "It's a sword of Damocles hanging over you, especially the period between giving them the blood and receiving the test results." [13]

HCWs can address these anxieties in different ways. The HDSA recommends "psychological and/or psychiatric screening" for depression and emotional support. ${ }^{18}$ Here, several individuals were referred to psychiatrists who prescribed antianxiety medications as well. Hence, an added benefit of genetic counseling could be referral to mental health services that are not otherwise accessed. GCs themselves also responded to patients' fears, e.g., by not knowing the test result before disclosing it.

\section{I was most scared about the walk from the waiting room to where they were going to tell me... How the hell do you walk from one place to the other with a person who knows? So the counselor actually set up this elaborate plan where she was not going to know, and was going to pick me up and walk me from the waiting room to the room where I found out. So I wouldn't have to walk with someone who knew when I didn't know. ${ }^{[12]}$}

HCWs can reveal their suspicions about the presence of the gene through not only verbal, but inadvertent, nonverbal communication, too. Similarly, when becoming aware of a patient's HD risk or symptoms, staff may change their tone of voice. ("As soon as the HD discussion came up, the doctor got very, very serious, and closed the door. He sat down and gave us the numbers. He frightened us." ${ }^{[7]}$ ) Consequently, HCWs need to be sensitive to not only verbal but nonverbal interactions about these issues.

However, regardless of the HCW's sensitivity with gene positive test results, the process of giving the news can never be wholly "good," no matter how the process operates.

We saw the counselor's face and knew in 2 seconds, because she is a very la de da, very happy person ... It was shock... We just got the news and walked out. There was no counseling. Nothing. She called up over the weekend. But it was such a definite thing... here's the results, thank you very much. See you later. ${ }^{[7]}$

The counselor may have in fact provided additional support, but under the circumstances, it may not have registered.

Frequently, the counseling process was seen as too long and intense. GCs were often seen as playing the role of devil's advocate, repeating the same questions. Yet generally, in retrospect, individuals came to understand the reasons why the process took so long. 
... they kept asking the same questions too many times ... "Do you really want to go through with this? Why ... ? What purpose can it possibly serve?" When I look back, I understand why... But they were persistent and annoying ... They might just say, "Look, you're going to get annoyed with us. We're going to ask some of these questions over and over again, but realize there's a reason... You just don't know it yet... " They even may have said that, and I filtered it out. ${ }^{[13]}$

Hence, counselors could potentially set expectations more realistically by more thoroughly describing the process in advance, and ensuring that it is understood over time.

At-risk individuals who had science training, in particular, felt the process was too long.

The testing process can take 6 months: too long for me... Most people... need that. But if someone wants to know in a hurry, and knows his or her own mind, and is able to tell them, they should do it quickly. ${ }^{[21]}$

Several lay individuals also felt that the lengthy process was not wholly applicable to them because they had already seriously considered and weighed the options. Hence, these data highlight the need for flexibility in the process.

They really drill you. I understand why . . But I felt I had a very good reason to get tested. I didn't waiver... Not everyone is so ready, or has thought it through as carefully as I did. [4]

Indeed with time, many who initially, without counseling, wanted to test immediately became aware of the complexity of the issues and appreciative of the need for thoroughness in the process.

My husband and I wanted to know right away... I didn't need the counseling... But then as it turned out, talking to staff here: "O.K., we're not ready to go through with this." The biggest question they asked us was, "What do you want to do if it comes back positive? What's your reaction going to be?" That was the killer question. ${ }^{[7]}$

In this case, genetic counseling clearly served its intended purpose well, prompting individuals to consider all possible scenarios.

Certain aspects of the counseling process proved most helpful, particularly presentations of questions that clients had not considered, as just suggested, and of metaphors and ways of understanding the dilemmas and phenomena involved.

They said to view it like a NY apartment:

You have a tiny NY apartment, and are so tight for space, and spend ages organizing your closet, because you only have one.

That's the same thing with the HD: if you know this is the amount

of time you have, you can make the best of it. ${ }^{[7]}$

In large part, GCs helped due to innate empathy, not necessarily professional training per se. "She genuinely cares. It's not part of her job or training. You think: 'At least I'm not alone."'[7]

Importantly, strong, reliable, and ongoing social support can not only help with the content of decision making, but with overcoming feelings of isolation and aloneness.
As suggested earlier, referral to mental health services can be especially beneficial. Psychotherapy can play several key roles and prove critical in making testing decisions and accepting results.

I'm really at peace right now. . . 10 years ago, I would have been bonkers about the thought of having a genetic disease. But I've been seeing my psychologist. [18]

Psychotherapy assisted here with acceptance, but can be helpful even if not yet leading to complete acceptance of one's risk status.

My sister is too scared to know . . . but is really at a different point than 10 years ago, too, when she first started seeing her therapist: it's not on her mind all the time like it used to be. ${ }^{[18]}$

Hence, psychotherapy can reduce the degree of preoccupation with either the threat of HD or the uncertainties inherent in decision making, lowering the level of anxiety involved in testing decisions. Consequently, mental health treatment can be an important adjunct to genetic counseling.

[My therapist] is extremely helpful and I would recommend no one go through testing unless they have someone who's really smart to help them through it. ${ }^{[12]}$

\section{Looking back at testing decisions}

Even when receiving a mutation-positive result, these individuals generally did not regret their decisions. Most felt that their ultimate choice was right for them. Still, retrospective assessment was hard, and might be biased by the test result, previous assumptions, and subsequent decisions.

Not surprisingly, those who tested negative tended to have few regrets. "The results of my decision make it impossible for me to look back at my decision... It worked out well for me." ${ }^{[12]}$

But those who tested positive generally did not rue their decision to be tested either.

The test itself has been an unambiguous, positive thing for me. I have not had a single moment, not even in passing, that I wish I hadn't known. I had been aware of HD my whole life. . . The test result made me feel that the decisions I made in my life were good.[15]

Importantly, counseling helped in enabling individuals to feel that their decision was appropriate for them.

Still, even those who felt that testing was beneficial for them veered from recommending it for everyone. "What we did was the right thing to do for $u s . "{ }^{[7]}$

\section{DISCUSSION}

These data highlight several critical aspects of the roles of social interactions and processes in decisions concerning genetic counseling and testing for HD. These interactions with family members, HCWs, and others proved important and complex, but have been relatively underexamined. Specifically, many decision-making theories applied to testing for 
$\mathrm{HD}^{16,17,21,70,71}$ and other genetic conditions ${ }^{39,72}$ have focused on individual cognitive and emotional factors, drawing on psychological models and emphasizing, for example, traits of seeking or avoiding information and being risk averse. ${ }^{23,25,73}$ But the current data reveal how individuals make these decisions in social relationships and contexts with multiple sets of others, particularly family members (e.g., spouses, siblings, current and future offspring) and HCWs (e.g., with or without specialized knowledge of $\mathrm{HD}$ ). Although one previous Australian study suggested that individuals considered family members' hypothetical responses, ${ }^{36}$ in the present investigation, family members communicated directly their views of an individual's testing decisions and could affect those decisions. Perceived responsibilities toward others have been found to affect reproductive decisions among individuals at risk of $\mathrm{HD}^{34}$ and at times conflict. ${ }^{35}$ Here, others' interactions also shaped testing decisions and could clash as well both with each other and with an individual's own preferences. A wide range of interactions occurred, often involving competing views and moral dilemmas and eliciting a variety of responses and difficult compromises and negotiations. At-risk individuals may be inclined to avoid testing, but overcome that tendency to help their offspring; or an individual may tend to seek testing, but be deterred because of fear of discrimination to his or her family. These types of social input shaped individuals' decisions about not only whether, but when to test. Although delays in testing have been noted, ${ }^{17}$ the present data illustrate the key roles of social factors involved in such delays.

Importantly, for genetic tests, arguably more than for many other kinds of tests, HCWs served as crucial gatekeepers. Although HCWs who are not geneticists or GCs frequently have deficits in genetics knowledge and do not feel comfortable providing genetic counseling, ${ }^{45-49,52}$ the present data suggest that these HCWs often are nonetheless involved in these decisions. However, such physicians appeared here to follow a bimodal pattern: some may encourage testing too much, whereas others do so too infrequently. Both of these extremes appeared to stem from limitations in knowledge.

Despite HDSA guidelines about testing, ${ }^{37}$ interviewees reported varying views and experiences concerning the testing and counseling processes themselves. For genetic tests, more so than for nongenetic tests, patients, whether legitimately or not, may see HCWs as judging patients' rationales (particularly reasons not considered strictly medical, e.g., "just wanting to know").

Although the HDSA recommends that individuals "not be coerced" to test, ${ }^{18}$ these data indicate that family members may nonetheless apply strong pressure on an individual. Indeed, perceptions and definitions of coercion range widely, ${ }^{28}$ and an at-risk individual may choose to place family members' wishes over his or her own because of the relative strengths of each of these sets of preferences or fears of those members' reactions otherwise. Importantly, clinicians should be aware of the presence of such actual or perceived pressures.

Questions emerged about what roles HCWs, especially physicians, should have in these decisions. No other study has explored patients' perceptions of the roles of HCWs in testing decisions. These findings support reports of knowledge deficits among HCWs who do not have specialized training in genetics. Yet these data indicate that patients are nonetheless communicating with such HCWs about these issues and at times are in fact aware of these providers' deficits. Although previous research found deficits in HCW genetic knowledge and risk assessment skills, the current data suggest deficits in communication and sensitivity concerning HD testing issues as well. However, if physicians demonstrate or suggest relative ignorance or insensitivity about these areas, patients might instead seek information on the Internet or through direct-to-consumer marketers of tests, which may not be as trustworthy, and confidence or trust in physicians concerning these and related areas may decrease.

These data support HDSA recommendations for "psychological and/or psychiatric screening ... based on the high levels of depression found." ${ }^{37}$ Indeed, this study suggests that mental health services may frequently be helpful, particularly because HD can precipitate psychiatric symptoms either directly or indirectly. Anxiety, too, arose here as a symptom. Symptoms in parents who suffer from the disease can also psychologically affect children. Such early "life trauma" can contribute to stresses that make the receipt of genetic test results later in life more difficult. Psychotherapy can help in addressing these issues. These data pose questions for future research of how often and well such psychological screening in fact occurs, particularly because other studies have suggested that physicians who are not psychiatrists often have poor training and abilities in screening for psychiatric disorders. ${ }^{74}$

Larger social contexts shaped decision making here as well. Given that HCWs are purveyors of knowledge and gatekeepers of referrals for tests, these data underline the importance of institutional, historical, and geographic contexts, which have been underexplored. We have found no studies on HD testing decisions that have commented on possible differences among industrialized countries (e.g., Canada, versus the United States versus the United Kingdom) that have different insurance systems. Despite HIPAA, discrimination concerns for oneself and one's offspring arose here, but have not been mentioned in some previous studies in Australia and Canada, where health care is nationalized and hence guaranteed. ${ }^{14,30}$ Indeed, HD testing rates appear higher in Canada than in the United States. 5,75

These contexts can also shift over time. Since several previous studies were conducted, testing technologies have advanced, and linkage tests are no longer used. Hence, the difficulty of obtaining blood from relatives did not emerge here as a reason not to test, as it has in the past. ${ }^{12}$ Importantly, adults can also now undergo testing to decide whether they or their adult offspring should consider the costly, and not entirely benign, procedure of PGD. ${ }^{54,55}$ Although in the past, a leading reason to test was "if my risk goes up, so does that of my children"12; PGD now enables mutation-positive parents to avoid passing on the mutation, ${ }^{56,57}$ furthering the possible roles of social factors in testing decisions (i.e., to inform adult 
offspring whether they are at potential risk and should therefore undergo PGD).

From a theoretical perspective, these data underscore the importance of viewing decision making about genetic testing not as individualistic and unilateral, but as dynamic, social. and interactive. That is, individuals often make decisions not alone, but with input from several key sets of others. As suggested by the health belief model, these individuals do weigh the pros and cons about their decisions. But although this theory is largely a rational decision model, the present data shed light on the roles of social contexts and interpersonal pressures, involving implicit and explicit authority. Individuals must weigh complex moral factors (e.g., others' perceptions of justice) and decide whether to reject or accept such input and, if the latter, to what degree. Moreover, individuals also take into account the actual or perceived potential effects of their decisions on others. Thus, such a health belief model should not be viewed in isolation or as simply a rational weighing of the pros and cons. Rather, the decision-making process is complex, subjective, and interpersonal, taking place in dynamic social settings that can profoundly shape it.

Hence, these data highlight the need for theories that make sense of these unique social aspects of genetics. Genetic disease has direct social implications for not only the individual undergoing the testing, but his or her family as well (i.e., in terms of health and potential discrimination). Thus, family members may have strong feelings that they express about an individual's testing decisions. These social implications may also in turn affect HCWs' approaches with a patient (e.g., increasing HCWs' encouragement of testing). Thus, genetics may require different models of decision making than in other areas of medicine. For instance, while theories on health information have described traits of monitoring versus blunting, the present data also suggest that these tendencies get weighed against these other, at times competing, social factors (e.g., the preferences, needs, and moral claims of others). The strength or degree of tendencies toward monitoring versus blunting may compete with the degree of perceived pressure from others. Although "social learning theory" has also been described, suggesting that individuals model behavior on others, ${ }^{76}$ the present data indicate the need to develop and refine a "social genetic decision-making theory," which this article hereby proposes, suggesting that the preferences and desires of others shape an individual's decision making, not through modeling, but through the social contexts and implications of genetic information on others. GCs and other HCWs should recognize and address such social processes as much as possible.

Recently, in decision making involving conflicting values (e.g., between a patient and his or her family members), "clinical pragmatism" has been advocated (as opposed to principlism), emphasizing the importance of interpersonal processes $^{77}$ such as those here. An "arbitration" model 78 has similarly been advocated. Both models encourage exploration of all competing views in such disputes. HCWs, in addressing disagreements that they may face concerning genetic testing, may benefit from awareness of such models.
Because HD is an autosomal-dominant neurodegenerative disorder of adult onset, some aspects of testing for it are unique and not identical to those posed by testing for other genetic diseases. Nonetheless, this study has several important implications for certain other genetic conditions. As with other adult onset disorders (e.g., breast cancer, $\alpha_{1}$-antitrypsin deficiency, and familial adenomatous polyposis), patients may see genetic test results for HD as reflecting an innate, unalterable part of themselves, potentially threatening their future health, having implications for the future health of other family members, and possibly leading to future discrimination and stigma against themselves or their families. Consequently, for these other disorders as well, social factors and contexts (e.g., the views and input of family members and HCWs) may play vital roles in shaping individual decisions to test or not in ways of which HCWs, in general, need to be aware.

These data thus have critical implications for professional and public education. HCWs (both in genetics and other fields), family members, and at-risk individuals can benefit from being more aware of and prepared to address these complexities. At-risk individuals may be aided by HCWs' and family members' being as sensitive and supportive as possible concerning these tensions that may arise. Because many physicians completed their training before genetic testing for HD and other disorders was available, problems emerge concerning appropriate provider communication and practice, how physicians do and should handle new genetic knowledge. Clearly, education is needed regarding not only the science of genetics, but the intricacies and sensitivities involved in interacting with patients about these decisions and the meanings and interpretations of test results. Physicians outside of genetics may hesitate to admit knowledge deficits to patients (e.g., saying "I really don't know much about this field or test, but can refer you to a specialist.") Rather, doctors operate usually from positions of authority that they may seek to maintain.

These data have practice implications as well, offering several specific suggestions for helping HCWs be as effective as possible concerning these issues. In part, given these social complexities in genetic testing, patients valued HCWs' compassion, not only their technical skill. Nonverbal or inadvertent communication affected patients. Consequently, providers can arrange, for example, not to know results before sharing them with clients. It might be helpful also for HCWs to convey (and perhaps periodically remind clients) as clearly as possible of the reasons for the lengthy genetic counseling process involved. HCWs also need to work more closely with and educate spouses and other family members, given the substantial roles these members may have in testing decisions. HCWs, particularly those without specialized knowledge of genetics, may benefit from understanding further the complexities involved in not only whether but when to test. These data highlight as well the importance of HCWs' paying attention to the psychiatric and psychotherapeutic issues involved, entailing anxiety and other symptoms and arising either directly or indirectly from HD. Although the HDSA recommends a multidisciplinary team, ${ }^{37}$ 
it is unknown how often HCWs, including GCs, actually note, or refer individuals for, mental health problems, especially in locations that may have fewer mental health providers. The fact that some at-risk individuals do not want to use insurance poses additional potential challenges because adequate mental health treatment is often not well covered by insurance. This area should be addressed by researchers and policymakers.

These data also highlight the need to study more fully components and definitions of "adequate," "satisfactory," or "optimal" counseling and testing experiences, from patients' as well as HCWs' perspectives. However, these data underscore also the difficulties of evaluating these processes and HCWs' roles in them, especially retrospectively. Past studies of posttest responses have not examined differences in the amount or type of genetic counseling. ${ }^{56}$

In short, it is not clear how frequently a "team approach" occurs, what it looks like, what kinds of follow-up occur over time, who initiates it, and of what it consists. Future research can examine in further detail the quantity and quality of these processes, staff background and amounts of experience, costs involved, specific contents of GC discussions, and differences in perceived adequacy and satisfaction. As testing moves from academic medical centers to wider routine clinical practice in diverse settings, such variations in the quality of counseling are vital to comprehend. Concomitantly, the increase of direct-to-consumer marketing of genetic tests may lead patients to inquire about testing more frequently with HCWs. Policymakers also need to assess whether and to what degree insurance coverage of these services should be increased and regulated.

Further research is needed as well regarding how exactly HCWs vary (e.g., by type and recency of training) in approaches to genetics. It remains unclear what kinds of physicians (e.g., GPs, family physicians, or neurologists) order, or refer patients for, HD tests and in what ways and how commonly. Future studies need to assess more fully how frequently HCWs, couples, parents, and offspring view testing and agree or disagree about it. Among HCWs, physicians (trained to be directive) may display more biases than GCs (trained to be nondirective). But the extent to which GCs are in fact nondirective and neutral, the degree to which they vary, and what factors are associated with such variation are unclear. Indeed, among GCs, men have been found to be more directive than women. ${ }^{79}$ Whether GCs are perceived to or, in fact, do have preferences remains unknown.

This study has several potential limitations. We interviewed participants at one point in time only, yet they described their past and current HD-related experiences. We only interviewed the patient, not the HCW or other family members about the patient's report concerning the perceptions and input of these other individuals. However, patients' perceptions are important in and of themselves because patients are responding to their views of the roles of, and interactions with, others. Future research can investigate dyads of HCWs and their patients concerning their joint interactions. These interviewees were fol- lowed at a tertiary care center. Hence, they may have had greater than average knowledge of HD and access to resources, but they provided key insights into responses to HD by parents, siblings, and extended relatives at many other institutions as well. Although these individuals were from one geographic area, they described their own and their family members' interactions in numerous clinics and areas, and no evidence has emerged that views of HD decisions vary among geographic areas in the United States. Further research can, however, assess this possibility as well.

In sum, these data have several critical implications for future clinical care, professional and public education, research, and policy concerning decision-making processes about genetic testing for HD and potentially for certain other disorders as well.

\section{APPENDIX: SAMPLE QUESTIONS FROM SEMISTRUCTURED INTERVIEW GUIDE}

- When did you learn that you were at risk of HD and what was your reaction to it at that time?

- How do you feel about being at risk of HD?

- Have you had genetic testing done?

- If so, what was the result and how did you respond?

- How did you decide whether to have genetic testing done or not?

- What factors were involved in your decisions?

- Have you ever felt stigma or discrimination because of $\mathrm{HD}$ ?

- Have you been concerned about threats to privacy? How so?

- Have HCWs been involved in your testing decision? If so, how?

- Do you have any other thoughts about these issues?

\section{ACKNOWLEDGMENTS}

Funding for this research was provided through grant 5-R01-HG002431-01 from the National Human Genome Research Institute, and the Huntington's Disease Society of America. The authors thank James Zvokel, Antonius Wiriadjaja, Kristin Skrabut, Renée C. Fox, Carol Moskowitz, Paula Wasserman, Wendy Chung, and Joseph Siragusa for their assistance with this manuscript.

\section{References}

1. Kessler S, Field T, Worth L, Mosbarger H. Attitudes of persons at risk for Huntington disease toward predictive testing. Am J Med Genet 1987;26:259-270.

2. Markel DS, Young AB, Penney JB. At-risk persons' attitudes toward presymptomatic and prenatal testing of Huntington disease in Michigan. Am J Med Genet 1987; 26:295-305.

3. Mastromauro C, Myers RH, Berkman B. Attitudes toward presymptomatic testing in Huntington disease. Am J Med Genet 1987;26:271-282.

4. Meissen GJ Berchek RL. Intended use of predictive testing by those at risk for Huntington disease. Am J Med Genet 1987;26:283-293.

5. Creighton S, Almqvist EW, MacGregor D, Fernandez B, et al. Predictive, pre-natal and diagnostic genetic testing for Huntington's disease: the experience in Canada from 1987 to 2000. Clin Genet 2003;63:462-475.

6. Hayden M. Predictive testing for Huntington's disease: the calm after the storm. Lancet 2000;356:1944-1945. 
7. Wexler NS. Genetic "Russian Roulette": The Experience of being "at risk" for Huntington's Disease. In: Kessler SJ, editor. Genetic counselling: psychological dimensions. New York: Academic Press, 1979: 199-200.

8. Quaid K, Brandt J, Faden R, Folstein S. Knowledge, attitude, and the decision to be tested for Huntington's disease. Clin Genet 1989;36:431-438.

9. Evers-Kiebooms G, Decruyenaere M. Predictive testing for Huntington's disease: a challenge for persons at risk and for professionals. Patient Educ Couns 1998;35: 15-26.

10. Meissen G, Mastromauro CA, Kiely DK, McNamara DS, et al. Understanding the decision to take the predictive test for Huntington disease. Am J Med Genet 1991; 39:404-410.

11. Robins-Wahlin TB, Backman L, Lundin A, Haegermark A, et al. High suicidal ideation in persons testing for Huntington's disease. Acta Neurol Scand 2000;102: 150-161.

12. Quaid K, Morris M. Reluctance to undergo predictive testing: the case of Huntington disease. Am J Med Genet 1993;45:41-45.

13. Baum A, Friedman AL, Zakowski SG. Stress and genetic testing for disease risk. Health Psychol 1997;16:8-19.

14. Cox SM. Stories in decisions: how at-risk individuals decide to request predictive testing for Huntington disease. Qual Sociol 2003;26:257-280.

15. Prochaska JO, DiClemente CC, Norcross JC. In search of how people change: applications to addictive behaviors. Am Psychol 1992;47:1102-1114.

16. Houlihan GD. The evaluation of the 'stages of change' model for use in counselling client's undergoing predictive testing for Huntington's disease. J Adv Nurs 1999;29: 1137-1143.

17. Taylor SD. Predictive genetic test decisions for Huntington's disease: elucidating the test/no-test dichotomy. J Health Psychol 2005;10:597-612.

18. Rosenstock IM, Strecher VJ, Becker MH. Social learning theory and the Health Belief Model. Health Educ Q 1988;15:175-183.

19. Fang CY, Dunkel-Schetter C, Tatsugawa ZH, Fox MA, et al. Attitudes toward genetic carrier screening for cystic fibrosis among pregnant women: the role of health beliefs and avoidant coping style. Womens Health 1997;3:31-51.

20. Folkman S, Lazarus RS. An analysis of coping in a middle-aged community sample. J Health Soc Behav 1980;21:219-239.

21. Gooding HC, Organista K, Burack J, Bowles Biesecker B. Genetic susceptibility testing from a stress and coping perspective. Soc Sci Med 2006;62:1880-1890.

22. Wilson TD. On user studies and information needs. Available at: http://informationr. net/tdw/publ/papers/1981infoneeds.html. Accessed August 4, 2006.

23. Tversky A, Kahneman D. The framing of decisions and the psychology of choice. Science 1981;211:453-458.

24. Miller SM. Monitoring and blunting: validation of a questionnaire to assess styles of information seeking under threat. J Pers Soc Psychol 1987;52:345-353.

25. Case DO, Andrews JE, Johnson JD, Allard SL. Avoiding versus seeking: The relationship of information seeking to avoidance, blunting, coping, dissonance, and related concepts. J Med Libr Assoc 2005;93:353-362.

26. Fox R. The sociology of medicine: a participant observer's view. Englewood Cliffs, NJ: Prentice-Hall, 1989

27. Kleinman A. The illness narratives: suffering, healing \& the human condition. New York: Basic Books, 1988.

28. Parsons T. On the concept of influence. In: Parsons T. Sociological theory and modern society. New York: Free Press, 1967.

29. Gifford SM. The meanings of lumps: a case study of the ambiguities of risk. In: Janes C, Stall R, Gifford SM, editors. Anthropology and epidemiology: interdisciplinary approach to the study of health and disease (culture, illness and healing). Boston: Reidel Publishing Co., 1986: 213-246.

30. Cox SM, McKellin W. 'There's this thing in our family': predictive testing and the construction of risk for Huntington disease. Sociol Health Illn 1999;21:622-646.

31. Sobel SK, Cowan DB. Impact of genetic testing for Huntington disease on the family system. Am J Med Genet 2000;90:49-59.

32. Richards F, Williams K. Impact on couple relationships of predictive testing for Huntington disease: a longitudinal study. Am J Med Genet 2004;126A:161-169.

33. Hamilton RJ, Bowers BJ, Williams JK. Disclosing genetic test results to family members. J Nurs Scholarsh 2005;37:18-24

34. Downing C. Negotiating responsibility: case studies of reproductive decision-making and prenatal genetic testing in families facing Huntington disease. J Genet Couns 2005;14:219-234.

35. Klitzman R, Thorne D, Williamson J, Chung W et al. Decision-making about reproductive choices among individuals at-risk for Huntington's disease. J Genet Couns 2007 May 1; [E-pub ahead of print].

36. Taylor SD. Predictive genetic test decisions for Huntington's disease: context, appraisal and new moral imperatives. Soc Sci Med 2004;58:137-149.

37. Huntington's Disease Society of America, Inc., 1994 Guidelines for Genetic Testing for Huntington's Disease. Available at: http://dwb.unl.edu/Teacher/NSF/C08/
C08Links/www.hdfoundation.org/testread/hdsatest.htm. Accessed January 15 2007.

38. Wertz DC, Sorenson JR. Client reactions to genetic counseling: self-reports of influence. Clin Genet 1986;30:494-502.

39. Aktan-Collen K, Mecklin JP de la Chapelle A, Peltomäki P, et al. Evaluation of a counselling protocol for predictive genetic testing for hereditary non-polyposis colorectal cancer. J Med Genet 2000;37:108-113.

40. Sher C, Romano-Zelekha O, Green MS, Shohat T. Factors affecting performance of prenatal genetic testing by Israeli Jewish women. Am J Med Genet 2003;120A: $418-422$.

41. Copley TT, Wiggins S, Dufrasne S, Bloch M, et al. Are we all of one mind? Clinicians' and patients' opinions regarding the development of a service protocol for predictive testing for Huntington disease. Canadian Collaborative Study for Predictive Testing for Huntington Disease. Am J Med Genet 1995;58:59-69.

42. Wideroff L, Freedman AN, Olson L, Klabunde CN, et al. Physician use of genetic testing for cancer susceptibility: results of a national survey. Cancer Epidemiol Biomarkers Prev 2003;12:295-303.

43. Cho MK, Sankar P, Wolpe PR, Godmilow L. Commercialization of BRCA1/2 testing: practitioner awareness and use of a new genetic test. Am J Med Genet 1999;83: 157-163.

44. Suther Menasha JD, Schechter C, Willner J. Genetic testing: a physician's perspective. Mt Sinai J Med 2000;67:144-151.

45. Freedman AN, Wideroff L, Olson L, Davis W, et al. US physicians' attitudes toward genetic testing for cancer susceptibility. Am J Med Genet 2003;120A:63-71.

46. Chase GA, Geller G, Havstad SL, Holtzman NA, et al Physicians' propensity to offer genetic testing for Alzheimer's disease: results from a survey. Genet Med 2002;4:297-303.

47. Baars MJH, Henneman L, ten Kate LP. Deficiency of knowledge of genetics and genetic tests among general practitioners, gynecologists, and pediatricians: a global problem. Genet Med 2005;7:605-610.

48. Barrison AF, Smith C, Oviedo J, Heeren T, et al. Colorectal cancer screening and familial risk: a survey of internal medicine residents' knowledge and practice patterns. Am J Gastroenterol 2003;98:1410-1416.

49. Burke S, Stone A, Bedward J, Thomas H, et al. A "neglected part of the curriculum" or "of limited use"? Views on genetics training by nongenetics medical trainees and implications for delivery. Genet Med 2006;8:109-115.

50. Schroy PC, Barrison AF, Ling BS, Wilson S, et al. Family history and colorecta cancer screening: a survey of physician knowledge and practice patterns. Am J Gastroenterol 2002;97:1031-1036.

51. Acheson LS, Stange KC, Zyzanski S. Clinical genetics issues encountered by family physicians. Genet Med 2005;7:501-508.

52. Giardiello FM, Brensinger JD, Petersen GM, Luce MC, et al. The use and interpretation of commercial APC gene testing for familial adenomatous polyposis. $N$ Engl J Med 1997;336:823-7.

53. Suther S, Goodson P. Barriers to the provisions of genetic services by primary care physicians: a systematic review of the literature. Genet Med 2003;5:70-76.

54. Biser A. Genetic information and employment: a report on law in the United States. Council for Responsible Genetics, January 2004. Available at: http://www.genelaw. info/reports/employment.pdf. Accessed July 19, 2006.

55. AAHP (American Association of Health Plans). Managed Care Facts: Enrollment, Growth, Accreditation. October 1999. Available at: http://www.ahip.org/content/ default.aspx?bc $=41|331| 358$. Accessed February 13, 2006.

56. Moutou C, Gardes N, Viville S. New tools for preimplantation genetic diagnosis of Huntington's disease and their clinical applications. Eur J Hum Genet 2004;12:10071014.

57. Jasper MJ, Hu DG, Liebelt J, Sherrin D, et al. Singleton births after routine preimplantation genetic diagnosis using exclusion testing (D4S43 and D4S126) for Huntington's disease. Fertil Steril 2006;85:597-602.

58. Gollust SE, Wilfond BS, Hull SC. Direct-to-consumer sales of genetic services on the Internet. Genet Med 2003;5:332-337.

59. Brain K, Soldan J, Sampson J, Gray J. Genetic counseling protocols for hereditary non-polyposis colorectal cancer: a survey of UK regional genetics centres. Clin Genet 2003;63:198-204.

60. Geertz C. Interpretation of cultures: selected essays. New York: Basic Books, 1973.

61. Strauss A, Corbin J. Basics of qualitative research-techniques and procedures for developing grounded theory. Newbury Park, CA: Sage Publications, 1990.

62. Klitzman R, Bayer R. Mortal secrets: truth and lies in the age of AIDS. Baltimore: Johns Hopkins University Press, 2003.

63. Klitzman R. Double lives. New York: Oxford University Press, 2007.

64. Klitzman R, Daya S. A scientific bent: Challenges and changes in spirituality faced by doctors who become patients. Soc Sci Med 2005;61:2396-2406.

65. Klitzman R. Disclosures of illness by doctors to their patients: a qualitative study of doctors with HIV and other serious disorders. Patient Educ Couns 2006;64:277-284. [E-pub $2006 \mathrm{Jul} 24]$. 
66. Klitzman R. "Patient-time," "doctor-time," and "institution-time": perceptions and definitions of time among doctors who become patients. Patient Educ Couns 2007; 66:147-155. [E-pub 2006 Nov 27].

67. Klitzman R. Views of risks and benefits among doctors who become patients. Patient Educ Couns 2006, January 20 [E-pub ahead of print].

68. Klitzman R. Improving education on doctor-patient relationships and communication: the views of doctors who become patients. Acad Med 2006;81:447-453.

69. Guest G, Bunce A, Johnson L. How many interviews are enough? An experiment with data saturation and variability. Field Methods 2006;18:59-82.

70. Meiser B, Dunn S. Psychological impact of genetic testing for Huntington's disease: an update of the literature. J Neurol Neurosurg Psychiatry 2000;69:574-8.

71. Beck AT, Brown G, Berchick RJ, Stewart BL, et al. Relationship between hopelessness and ultimate suicide: a replication with psychiatric outpatients Am J Psychiatry 1990;147:190-195.
72. Codori AM, Petersen GM, Miglioretti DL, Larkin EK, et al. Attitudes toward colon cancer gene testing: factors predicting test uptake. Cancer Epidemiol Biomarkers Prev 1999;8:345-351.

73. Kahneman D, Tversky A. Judgment under uncertainty: heuristics and biases. Science 1974;184:1124-1131.

74. Margolis RL. Nonpsychiatrist house staff frequently misdiagnose psychiatric disorders in general hospital inpatients. Psychosomatics 1994;35:485-91.

75. Myers RH. Huntington's disease genetics. NeuroRx 2004;1:255-262.

76. Bandura A. Social learning theory. New York: General Learning Press, 1977.

77. Fins JJ, Bachetta MD, Miller FG. Clinical pragmatism: a method of moral problem solving. Kennedy Inst Ethics J 1997;7:129-143.

78. Dubler NN, Liebman CB. Bioethics mediation: a guide to shaping shared solutions. New York: United Hospital Fund, 2003.

79. Wertz DC, Fletcher JC. Attitudes of genetic counselors: a multinational survey. Am J Hum Genet 1988;42:592-600. 